\title{
The Situation of Population Ageing and Social Security for Elderly People in Nepal
}

\section{Background}

Population ageing is the dynamic process of demographic and socioeconomic transformation which reflects the increase in the share of the elderly on the total population. It is considered as the natural process. There may be the three major causes for the population ageing, first is the increasing the life expectancy, second is the decreasing fertility and third one is migration. Both the developed and developing countries of the world are experiencing the population ageing and there is a growing concern about the population ageing in the world.

In all countries worldwide, poverty is the single greatest obstacle to a secure old age. In less developed countries, the problems associated with old age are poor diet, ill-health and inadequate housing, which are all exacerbated by poverty. Furthermore, due to changes in lifestyles in the developing world, chronic illness is becoming endemic among many older people, because technical advances in medicine have far outrun social and economic development that allows for relatively disease-free living in developed countries.

Whether a population is young or old, or getting older or getting younger, it depends on the relative size of people at different age groups. In general, a population with more than 35 percent under age of 15 years is considered young and population with more than 10 percent aged 65 years and above is considered as old.

In Nepal the people above 60 years are considered as elderly. The population of Nepal is considered young as 39 percent of its total population is less than 15 years of age while 6.5 percent people are above 60 years of age and only 4.20 percent are above 65 years of age. But the proportion of the elderly is continuously increasing. According to the census of 2001, 6.5 percent among the total population was covered by the people above the age of 60 years that was only 2.43 percent in 1911.The elderly population in Nepal is growing steadily at the rate of $3.39 \%$ per year. And it is projected that the proportion of the elderly population will be doubled in 2017 on the basis of that we can say that Nepal is already in the process of population ageing with the demographic transition period.

As the relative size of the population of elderly is continuously increasing the elderly dependency rate computed for different time periods shows increasing trend from $7.5 \%$ in 1911 to $12.01 \%$ in 2001. Considering the time span of 90 years; the rate is very slow with the magnitude of only $0.05 \%$ increase per year but the proportion of elderly is already at the high magnitude.

\section{Discussion}

The status of the elderly in the family reflects the status of the elderly in the society. In recent days, depleting sociocultural value system, diversification in occupation from agricultural to non-agricultural, higher mobility of economically active persons for seeking job and better education, and replacing existing joint family system by nuclear family system have been causing problematic for the security of aged people in Nepal.

Most of the population related activities are focused on the reduction of the fertility and population control but the specific health needs of senior citizens are virtually ignored by the present health services system. And there is a great disparity among the people on the utilization of the available health and welfare services.

National Policies, Acts and Regulations addressing the need of social security of elderly

The government of Nepal has formulated a National policy on ageing and the problems of elderly have been addressed at a level in various act and their regulations.

The Civil Code1963 has provisions for elderly people in its section on property rights distribution. In Civil Code, $1963 \mathrm{sec} .10$, it is stated that; "If the parents want to live with a particular son or daughter, it has to be clearly stated in the Bandapatra (the legal note on property distribution) and that son and daughter should take care of the parents. If the older parents cannot survive on their own income and if the son/daughter with whom they are not living should take care of, feed, and clothe them as per their earning".

In Local Self Governance Act 1999 under the heading of duties, rights, and responsibilities of village development committee in the Local Self Governance Act 1999, there is a provision for protection and development of orphan children, helpless, women, older people and disabled.

Senior Citizen Policy 2058 has envisaged incorporating economic benefit, social security, health service facilities and honor, participation and involvement, and education as well as entertainment aspects to support the elderly people in having prestigious livelihood. The policy aims to 
enhance the respect and dignity of the elderly in their family, society and nation. It also determines to improve the potential of the Elderly so that they continue to be active and productive in national development, and to create opportunities to assist them to continue to be self-reliant.

Following the Madrid Plan of Action on Ageing, 2002, the Government of Nepal has formulated National Plan of Action on Ageing. This plan of action has attempted to include the various spheres like economic, social security, health and nutrition, participation and involvement, education and entertainment and legal of elders for their empowerment and well being. And the priority is given to the community based actions more than the institution based.

The Government of Nepal enacted the Senior Citizen Act, 2006 to ensure the social, economic and human rights of the elderly citizens. The purpose of the Act is to protect and provide the social security of elderly. This act also ensures to nourishment and health care of old age; to maintain their dignity; ensuring their property and have right for use of their property; special facilities and exemption of transportation fair for old age. The Senior Citizens Regulations 2065 provides guidelines for the effective implementation of the Senior Citizen Act. The regulation has tries to bring the Old Age Homes, Day Care Centers and Geriatric Centers under certain terms and conditions conducted by the various sectors.

\section{Existing Programs of the Government for the social security of the elderly}

Together with the global movement and according to the commitment expressed in the international forums government of Nepal has initiated to response the social security need of the elderly people and started some programmes at the national level. The Ninth Five Year Plan (1997-2002) pronounced the policy platform to improve the life of elderly people by emphasizing actions that would reinforce dignity, economic opportunities, respect and social security for the elderly. The programmes are mainly focused on the issue of health, financial support including old age allowance and provident fund, legal provisions for the protection of right of the elderly and old age homes for the helpless elderly. But the effectiveness and appropriateness of those programmes are still questionable.

Regarding the health of elderly: Jeshtha Nagarik Swashthopachar Sewa Karyakram Karyanyowan Nirdeshika 2061BS (Senior Citizens Health Facilities Program Implementation Guideline, 2061BS) was adopted by the council of ministers on 2061 Bhadra, which attempts to provide medical facilities to the old age people. The government has provision to establish Jeshtha Nagarik Swashthopachar Kosh (Senior Citizens Health Facilities Fund) in each district. The government allocates some fund each year for each district for the purpose. Following the "Senior Citizens Health Facilities Program Implementation
Guideline, 2061BS", the poverty affected elderly people are provided free medicine and treatment up to NRs.2000 at a time in all 75 districts from the fund. The Government has proclaimed through the budget speech of fiscal year 2066/ 67 that the government will provide free health service for heart and kidney patient of 75 years and above age. The fiscal year (2066/67) budget also has provision to establish one health center for the elderly "Aarogya Aashram" in each of the five development regions of the country. Now the government has launched Free Health Service Program and the elderly can also be benefited from the programme.

Regarding the financial security: The government is providing Old-Age-Allowance (OAA) of Rs. 500 per month to people of age 70 and above. The government provides Rs 500 per month for widow and helpless women above the age of 60 years. The allowances is managed by Ministry of Women, Children and Social Welfare and distributed through the local units of Ministry of Local Development at the village level. Old age allowance is another form of recognition for older people, but there is little understanding of the impact and access of the pension on older people. The government has pension scheme for retired public servants and their widows and children.

Regarding the rehabilitations services: Pashupati Bridashram is the only one shelter for destitute elderly people run by the government, which was established in 1976 as the first residential facility for elders which has the capacity for 230 people only. There are about 70 organizations registered with the government spread all over Nepal. Most of them are charity organizations. About 1,500 elders are living in these old-age homes at present.

Regarding the legal provision for the protection of the right of the elderly: The Interim Constitution of Nepal, 2006 (Art. 13) has made a provision for separate Act, Rules and Regulations specially to protect the rights of elders. In accordance with the Madrid International Plan of Action on Ageing (MIPAA) 2002, the government has already formulated and promulgated separate Acts, Rules and Regulations. The National Plan of Action, 2062 developed for senior citizens deals with various aspects such as economic and social security, health and nutrition, participation and involvement, education and entertainment and legal condition and reforms. These legal instruments emphasize both equity and equality for elders. The government has been supporting and promoting individuals, NGOs and the private sector organizations that are coming up to work for ageing population. Despite these initiatives, the government is severely limited by the available trained human resources and the fund for effective and efficient implementation of the legal and institutional provisions developed so far. In public transportations the people above the age of 60 years are legally provided the discount of $50 \%$. 


\section{Conclusion}

The increasing life expectancy and population ageing is considered as the greatest success and achievement of the twenty first century and also the success of the public health programs but the effective management of the population ageing is also a major challenge to the modern societies and accordingly Nepal is already in the process of population ageing. The primary action for the health and well being of the elderly in Nepal should be focused towards identifying the status of elderly people in Nepal.Without the baseline data and information of about the real scenerio of the status of the elderly further planning for the health and welfare of the elderly can't be conducted. Also there is a need of close coordination and collaboration between the seate and non-state agencies working for the health and well being of the elderly. Health and welfare programmes for the aaged people should be given priority, like: health promotive and preventive actions including the provision of the geriatric wards/units at the hospital and special care for the elderly.More focus should be based on the family and community based supprortive programmes for the elderly rather than the institution based rehabilitative services alone. And it is the responsibilty of all of us to work for the well being of the elderly people, respect them and help them to fulfill their need of socoal security. Legal provisions for the welfare and social security of the elderly people should be implemented strictly. The welfare mechanism should also address the need of the elderly people who didn't got the opportunity to serve as the government employee such as the provision of provident fund. There should be also the provision of special care for the homeless, helpless, disable and mentally ill elderly people should be provided by the state. Special attention towards the social security need of elderly is necessary to increase their quality of life and make their life productive.

\section{References:}

1. Geriatric centre Nepal: Status report on elderly people(60+) in Nepal on health, nutrition and social status focusing on research needs. March 2010.

2. Upreti CR. Ageing and Social Security System in Nepal: Scope and Challenges. Network of Asia-Pacific Schools and Institutesof Public Administration and Governance. [Annual Conference]. 4-6 December 2006

3. World Health Organization. Dept. of Noncommunicable Disease Prevention and Health Promotion. Active ageing : a policy framework. Geneva: World Health Organization; 2002.

4. Definition of an older or elderly person. Geneva: World Health Organization; 2011 [cited 2011 September 8]; Available from: http://www.who.int/healthinfo/ survey/ageingdefnolder/en/index.html.

5. World Health Organization. Regional Office for SouthEast Asia. Health of the elderly in south-east asia: a profile. New Delhei:. 2004(SEA/GER/17).

6. Chalise HN. Demographic situation of population ageing in Nepal. Kathmandu Univ Med J (KUMJ). 2006 Jul-Sep;4(3):354-62. 